\title{
Self-expandable metal stent in lumen-apposing metal stent (the SEMS-in-LAMS procedure): a simple salvage procedure after LAMS misplacement
}

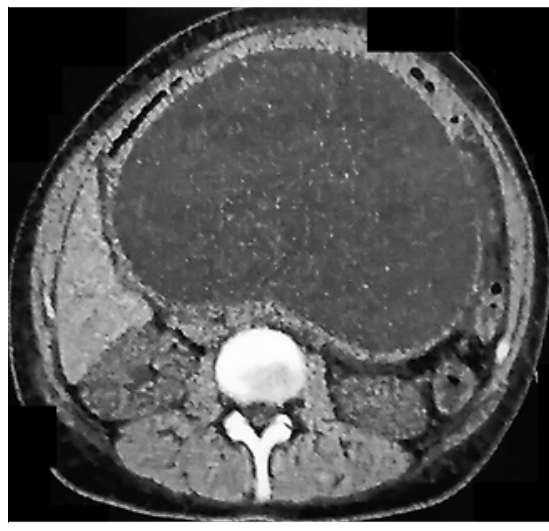

- Fig. 1 Computed tomography scan showing a large pancreatic pseudocyst $(20.3 \times 16.8 \times 15.0 \mathrm{~cm}$; total volume $2660 \mathrm{~mL})$.

Lumen-apposing metal stents (LAMSs) have been widely used for drainage of pancreatic fluid collections (PFCs) [1]. However, misplacement of stents is not rare and demands immediate intervention. We describe the use of a biliary selfexpandable metal stent (SEMS) placed through the LAMS to address misplacement during an endoscopic ultrasound (EUS)-guided drainage procedure.

In the first case, a 24-year-old woman presenting with a symptomatic PFC ( Fig.1) after an episode of moderate acute pancreatitis was referred for EUSguided drainage. During deployment of the LAMS $(3 \mathrm{~cm} \times 12-15 \mathrm{~mm}$; Hanarostent; Mitech), we accidentally released the proximal flange into the gastric wall. We pulled the stent towards the gastric lumen using a foreign body forceps, but the distal flange detached from the collection, dissecting the retroperitoneum ( Fig.2). We therefore placed a guidewire into the PFC through the LAMS using a pediatric endoscope. Finally, we deployed a biliary fully-covered SEMS $(10 \mathrm{~mm} \times 6 \mathrm{~cm}$; Hanarostent; Mitech) to connect the PFC to the stomach ( Video 1). Both stents were removed a month later without complications.

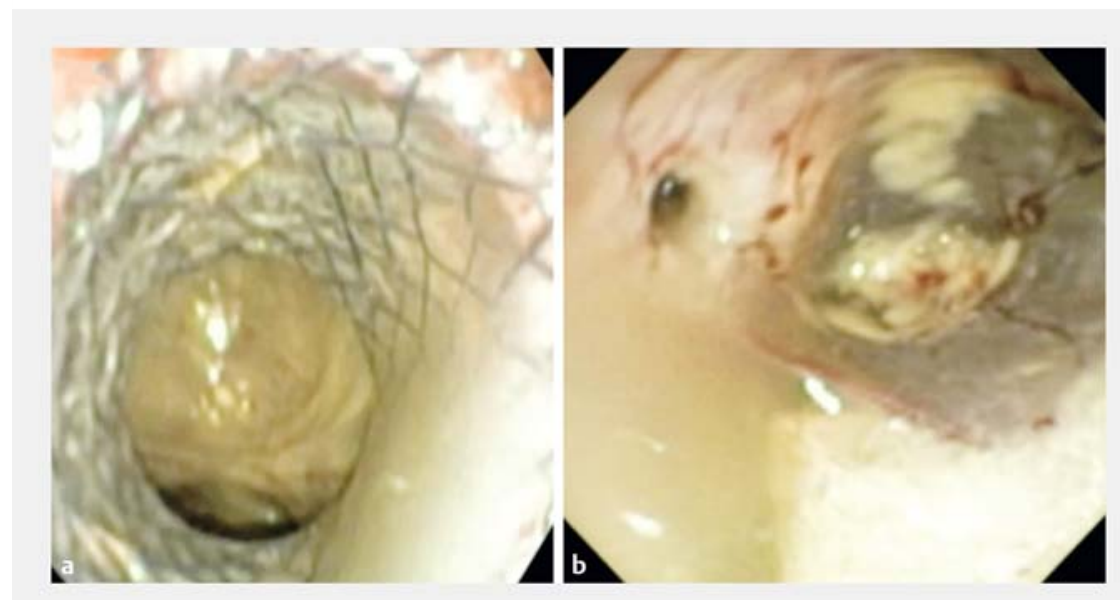

- Fig. 2 Endoscopic view of the lumen-apposing metal stent (LAMS) after traction with forceps showing: $\mathbf{a}$ the proximal flange of the LAMS in the gastric lumen; $\mathbf{b}$ the retroperitoneum and the orifice in the pseudocyst wall.

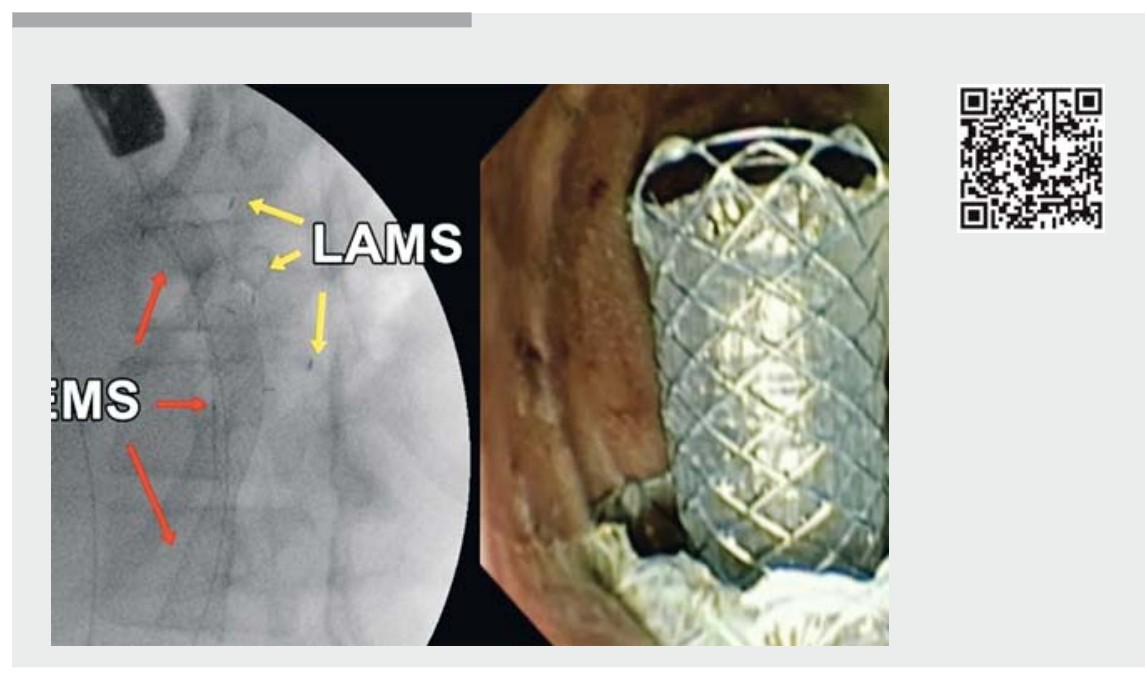

Video 1 Deployment of a self-expandable metal stent (SEMS) through a lumen-apposing metal stent (LAMS) after LAMS misplacement during endoscopic ultrasound-guided drainage of a pancreatic fluid collection: the SEMS-in-LAMS procedure.

In the second case, a 50-year-old man presenting with a symptomatic walledoff necrosis (> Fig. 3 ) after a severe episode of pancreatitis was referred for EUS-guided drainage. During the procedure, the proximal flange was accidentally deployed into the gastric wall (> Fig.4). Under EUS guidance, we intro- duced the sheath of the needle and a guidewire through the LAMS into the PFC. We deployed a fully-covered biliary SEMS inside the LAMS, thereby creating a communication between the PFC and the stomach ( $\triangleright$ Fig.5). Both stents were removed at 1-month follow-up without complications. 

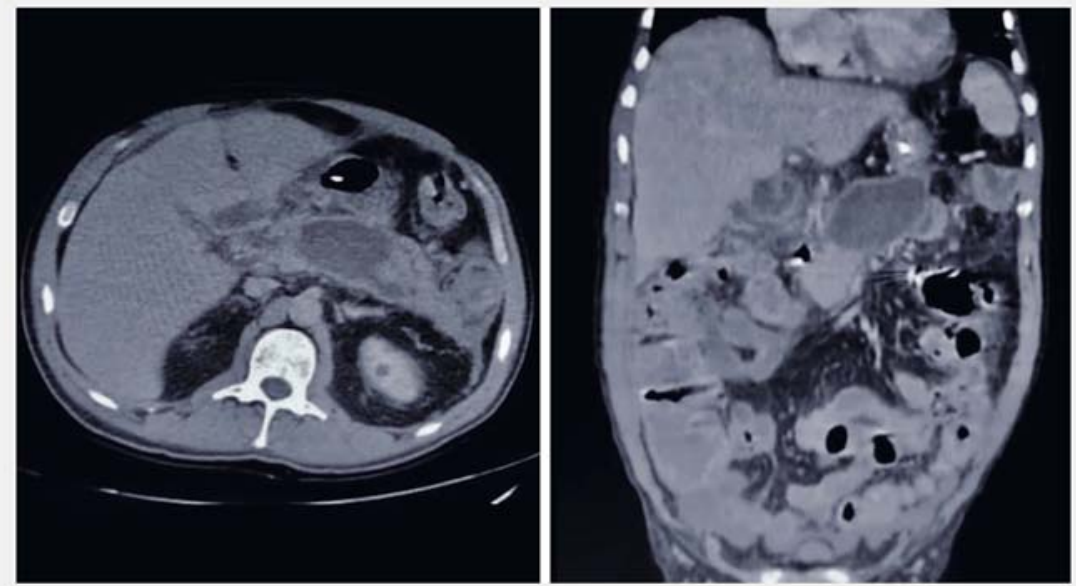

Fig. 3 Computed tomography scan showing a walled-off necrosis $(6.4 \times 4.1 \mathrm{~cm})$.
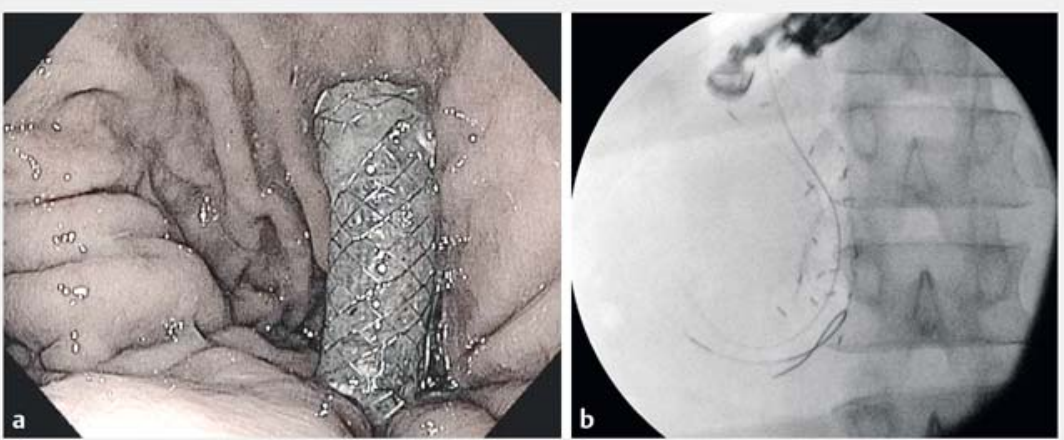

- Fig. 5 Final appearance of the self-expandable metal stent in lumen-apposing metal stent (SEMS-in-LAMS) procedure on: $\mathbf{a}$ endoscopic view; $\mathbf{b}$ radiographic view.

The short dumbbell shape of the LAMS draws together the wall of the collection and the lumen, thereby stabilizing the stent [2]; however, this short length may favor misdeployment. Ligresti et al. [3] recently reported a LAMS-in-LAMS procedure to address a buried stent. However, a standard biliary SEMS seems more appropriate to use as it is cheaper, widely available, and longer. This is the first description of the SEMS-in-LAMS procedure as salvage therapy after LAMS misplacement.

Endoscopy_UCTN_Code_CPL_1AL_2AD

Competing interests
The authors

Marcos E. Lera, Sérgio E. Matuguma, Antonio C. Madruga-Neto, Vitor O. Brunaldi, Maurício K. Minata, Hugo G. Guedes, Eduardo G. H. de Moura

Gastrointestinal Endoscopy Unit, Hospital das Clínicas, University of São Paulo Medical School, São Paulo, Brazil

\section{Corresponding author}

\section{Antonio Coutinho Madruga-Neto, MD} Hospital das Clínicas - University of São Paulo Medical School, Dr. Arnaldo Av, 455, 01246-903, São Paulo, Brazil antonio_coutinho_neto@hotmail.com antonio.cmneto@hc.fm.usp.br

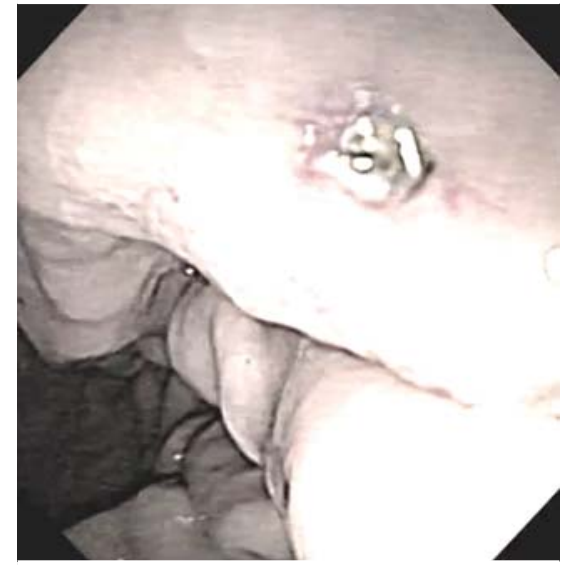

- Fig. 4 Endoscopic view showing the proximal edge of the lumen-apposing metal stent embedded into the gastric wall.

\section{References}

[1] Binmoeller KF, Shah J. A novel lumen-apposing stent for transluminal drainage of nonadherent extraintestinal fluid collections. Endoscopy 2011; 43: 337-342

[2] Shamah S, Okolo PI. Systematic review of endoscopic cyst gastrostomy. Gastrointest Endosc Clin N Am 2018; 28: 477-492

[3] Ligresti D, Cipolletta F, Amata M et al. Buried lumen-apposing metal stent (LAMS) following endoscopic ultrasound-guided gallbladder drainage: the LAMS-in-LAMS rescue treatment. Endoscopy 2018; 50: 822 - 823

\section{Bibliography}

DOI https://doi.org/10.1055/a-0820-1456

Published online: 23.1.2019

Endoscopy 2019; 51: E77-E78

(C) Georg Thieme Verlag KG

Stuttgart · New York

ISSN 0013-726X

\section{ENDOSCOPY E-VIDEOS \\ https://eref.thieme.de/e-videos}

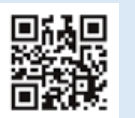

Endoscopy E-Videos is a free access online section, reporting on interesting cases and new techniques in gastroenterological endoscopy. All papers include a high quality video and all contributions are freely accessible online.

This section has its own submission website at https://mc.manuscriptcentral.com/e-videos 